\title{
A High Frequency of Allelic Loss in Oral Verrucous Lesions May Explain Malignant Risk
}

\author{
Catherine F. Poh, Lewei Zhang, Wan L. Lam, Xiaolei Zhang, Ding An, Cecil Chau, \\ Robert Priddy, Joel Epstein, and Miriam P. Rosin \\ Faculty of Dentistry (CFP, LZ, DA, RP), University of British Columbia, Vancouver; British Columbia Cancer \\ Research Centre (WLL, JE, MPR), Cancer Control Unit, Vancouver; and School of Kinesiology (XZ, CC, MPR), \\ Simon Fraser University, Burnaby, British Columbia
}

\begin{abstract}
SUMMARY: Verrucous carcinoma (VC), a variant of squamous cell carcinoma (SCC), is distinct from SCC in morphology and behavior. The underlying genetic changes involved in the development of $\mathrm{VC}$ and its precursor verrucous hyperplasia (VH) are unknown. This study determined whether chromosomal regions frequently lost during the development of SCC are also lost in the VH/VC variant. Twenty-five VH and 17 VC were analyzed for loss of heterozygosity (LOH) at 19 loci on 7 chromosome arms using microsatellite analysis. These data were compared with those from 47 reactive hyperplasias, 92 dysplasias (54 low- and 38 high-grade), and 41 SCCs. The results showed that VC/VH shared many of the losses present in dysplasia/SCC but differed in two aspects. First, VC/VH showed early acquisition of loss, compared with a gradual accumulation of losses from dysplasias to SCC. The LOH pattern of VH was similar to that of high-grade dysplasia and sharply different from reactive hyperplasia. The loss in $\mathrm{VH}$ often involved multiple arms (in $60 \%$ of $\mathrm{VH}$ vs $0 \%$ of reactive lesions). Only a marginal elevation of loss was observed at $9 p(p=0.06)$ and $4 q(p=0.05)$ from $\mathrm{VH}$ to VC because of the high degree of loss already present in $\mathrm{VH}$. Second, a strikingly lower frequency of loss at 17p was noted in VH/VC compared with dysplasia/SCC and may indicate human papillomavirus (HPV) involvement. The finding of high-risk $\mathrm{LOH}$ profiles in $\mathrm{VH}$ may partly account for the high-progression risk seen for $\mathrm{VH}$ and also has potentially important clinical implications. The difficult pathological diagnosis of VH/VC from reactive hyperplasia frequently requires repeated biopsies and results in delay in diagnosis and significantly increased mortality/morbidity. Microsatellite analysis might facilitate this differential diagnosis. (Lab Invest 2001, 81:629-634).
\end{abstract}

$O$ ral squamous cell carcinoma (SCC) is similar to SCC in many other organs (eg, uterine, cervix, skin, larynx, and pharynx) in that it is felt to develop in a multistep fashion through a series of histological stages with increasing risk of developing into invasive cancer, namely: epithelial hyperplasia; mild, moderate, and severe dysplasias; and carcinoma in situ (CIS). The presence of dysplasia and the breakage of the basement membrane (ie, invasion) are the hallmarks for judging malignancy in SCC (Fig. 1a). However, verrucous carcinoma (VC) (Fig. 1b), a variant of the conventional SCC in these organs, has unique clinicopathological features and biological behavior. VC and its precursor lesion, verrucous hyperplasia (VH) (Fig. 1c), are characterized by a prominent verrucous configuration, yet show minimal or no dysplasia and no breakage of the basement membrane. In the oral cavity, VC and SCC differ in the site of occurrence, with VC most commonly in the cheek and alveolus/ gingiva and SCC on the ventrolateral tongue and floor

Received January 29, 2001.

This work was supported by Grant No. 1 R01 DE13124-01 from National Institute of Dental and Craniofacial Research and by a grant from Natural Sciences and Engineering Research Council of Canada.

Address reprint requests to: Dr. Miriam Rosin, British Columbia Cancer Agency, Cancer Control Research Unit, 600 West 10th Avenue, Vancouver, BC, Canada, V5Z 4E6. E-mail: rosin@sfu.ca of mouth (Jacobson and Shear, 1972). VC does not metastasize, and it grows indolently (a 75\% 5-year survival rate for VC versus less than $50 \%$ for SCC), although the growth is so relentless that long-term prognosis may still be dismal. Despite these differences, a close relationship also exists between VC and SCC. VH and VC often coexist with dysplasia and SCC, and VH and VC have been reported to progress into SCC (Shear and Pindborg, 1980; Slootweg and Muller, 1983).

Recent studies using microsatellite analysis have shown the presence of genetic changes detected in the form of loss of heterozygosity (LOH) in oral dysplasia and SCC. The accumulation of changes in hyperplasias and dysplasias is associated with the risk of progression (Ah-See et al, 1994; Califano et al, 1996; Field et al, 1995; Mao, 2000; Mao et al, 1996; Partridge et al, 1998, Rosin et al, 1997, 2000; Roz et al, 1996; Zhang et al, 1997, 2000) and the response of these lesions to treatment (Zhang et al, 2001). The objective of the current study is to determine whether chromosomal regions frequently lost during the development of conventional SCC are also present in the VH/VC variant. This study used 19 microsatellite loci on 7 chromosome arms (3p, 4q, 8p, 9p, 11q, 13q, and $17 p)$ in a set of samples containing $\mathrm{VH}$ and $\mathrm{VC}$ and, for comparison, reactive hyperplasia, dysplasia, and SCC. 

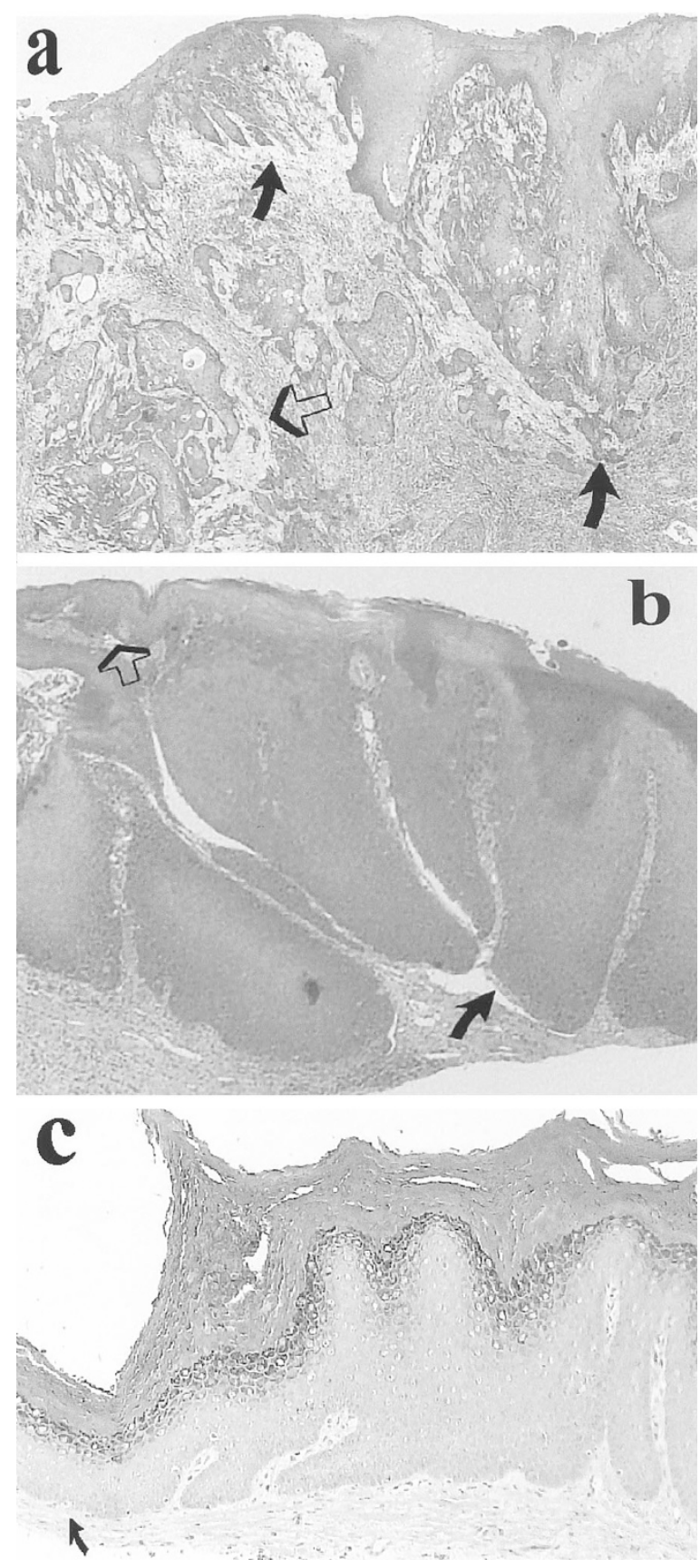

Figure 1.

a, Photomicrograph of an invasive squamous cell carcinoma (SCC). Solid arrows illustrate areas of tumor invasion with breakage of the basement membrane. Hollow arrow shows islands of invasive tumor cells deep in the connective tissue. b, Photomicrograph of a verrucous carcinoma (VC). Solid arrow shows that tumor growth is mainly endophytic with large bulbous rete ridges pushing downward relative to the normal location of the overlying oral epithelium (hollow arrow). The basement membrane is still intact. c, Photomicrograph of a verrucous hyperplasia (VH). The verrucous growth is exophytic (solid arrow indicates the normal location of the oral epithelium), and the basement membrane is intact.

\section{Results}

\section{Demographic Analysis of Sample Sets}

In this study, 224 cases belonging to six study groups were evaluated (Table 1). These groups did not differ significantly in gender composition. Data on smoking habits was available for $77 \%$ of the cases (172 of 224 cases), with a similar proportion of cases in each of the six groups lacking information. The percentage of smokers in each group ranged from $49 \%$ to $71 \%$, with no statistical difference between the groups. The lowest percentage of smokers was found in the reactive hyperplasia group. There was a trend toward increasing age with histological progression from reactive hyperplasia to low-grade dysplasia to highgrade dysplasia and, finally, to SCC ( $p<0.0001)$. No significant difference in age was noted between $\mathrm{VH}$ and VC or between VH/VC and SCC.

\section{Comparison of Allelic Loss between VH and Reactive Hyperplasia}

Reactive lesions are a heterogeneous group. We initially categorized these lesions into two subgroups. The first group contained lesions that appeared as white patches in the oral cavity and histologically demonstrated hyperkeratosis and/or acanthosis $(n=14)$. The second group included periodontitis, mucoceles, traumatic ulcers, and fibroepithelial polyps $(n=33)$. However, because these two groups did not differ in the frequency of loss at any of the above mentioned arms, we combined these subgroups together into the reactive-lesion group (Table 2 ).

$\mathrm{LOH}$ frequencies were significantly higher in $\mathrm{VH}$ compared with reactive lesions. The difference was especially striking for multiple losses (loss of more than one arm), which occurred in 15 of 25 (60\%) VH (Fig. 2a) but in none of the 47 reactive lesions ( $p=0.0001)$. $\mathrm{VH}$ consistently showed an elevated loss for each of the chromosome arms examined ( $p=0.0001-0.04$ ).

\section{Comparison of VH and Dysplasia}

Table 3 compares LOH frequencies of VH with lowgrade dysplasias (mild/moderate) and with those of high-grade dysplasias (severe dysplasia/CIS). In terms of the amount of loss observed, $\mathrm{VH}$ more closely resembles a high-grade lesion. $\mathrm{VH}$ shows a greater frequency of loss than low-grade dysplasia, which is apparent as an increase in mean loss $(p=0.0046)$, any loss $(p=0.081)$, and multiple loss $(p=0.026)$. In contrast, there was no significant difference in any of these parameters for $\mathrm{VH}$ versus high-grade dysplasias.

When individual arms were considered, $\mathrm{VH}$ showed increased loss at 3p, 4q, and 11q ( $p=0.02-0.03)$ and approached significance for $\mathrm{LOH}$ at $13 q(p=0.057)$ when compared with low-grade dysplasias. Similar frequencies for $\mathrm{VH}$ and low-grade dysplasias were observed at $9 p, 8 p$, and $17 p$. In contrast, when compared with high-grade dysplasia, $\mathrm{VH}$ showed a significantly lower loss only at $17 p(p=0.0007)$ and a marginally lower loss at $9 p$ (approaching significance, $p=0.057)$.

\section{Comparison of VH, VC, and SCC for Allelic Loss}

Table 4 compares LOH frequencies of $\mathrm{VH}$ with those of $\mathrm{VC}$ and $\mathrm{VC}$ with SCC (Fig. 2, b and c). $\mathrm{LOH}$ 
Table 1. Demographic Information

\begin{tabular}{lcccc}
\hline Diagnosis & No. of cases & Male $(\%)$ & Mean age $(95 \% \mathrm{Cl})$ & Smokers $($ ever $)(\%)$ \\
\hline Reactive oral lesions & 47 & 60 & $47(42-51)$ & 49 \\
Low-grade dysplasia & 54 & 44 & $54(50-58)$ & 59 \\
High-grade dysplasia & 38 & 55 & $62(58-66)$ & 57 \\
VH & 25 & 44 & $62(56-68)$ & 68 \\
VC & 17 & 47 & $69(63-75)$ & 71 \\
SCC & 43 & 59 & $63(60-67)$ & 66 \\
\hline
\end{tabular}

$\mathrm{Cl}$, confidence interval; $\mathrm{VH}$, verrucous hyperplasia; $\mathrm{VC}$, verrucous carcinoma; SCC, squamous cell carcinoma.

Table 2. Verrucous Hyperplasia versus Reactive Oral Lesions

\begin{tabular}{lccc}
\hline & $\begin{array}{c}\text { Reactive } \\
\text { lesions }\end{array}$ & VH & $p$ \\
\hline Number of cases & 47 & 25 & - \\
Mean loss & $0.19 \pm 0.4$ & $2.28 \pm 1.7$ & 0.0001 \\
Any loss & $9 / 47(19 \%)$ & $20 / 25(80 \%)$ & 0.0001 \\
Loss of more than & $0 / 47(0 \%)$ & $15 / 25(60 \%)$ & 0.0001 \\
one arm & & & \\
LOH on 3p & $5 / 44(11 \%)$ & $13 / 25(52 \%)$ & 0.0004 \\
$9 p$ & $1 / 46(2 \%)$ & $11 / 24(46 \%)$ & 0.0001 \\
$4 q$ & $0 / 43(0 \%)$ & $7 / 23(30 \%)$ & 0.0003 \\
$8 p$ & $0 / 45(0 \%)$ & $7 / 24(29 \%)$ & 0.0001 \\
$11 q$ & $2 / 44(5 \%)$ & $8 / 24(33 \%)$ & 0.003 \\
$13 q$ & $1 / 43(2 \%)$ & $4 / 22(18 \%)$ & 0.04 \\
$17 p$ & $0 / 45(0 \%)$ & $5 / 25(20 \%)$ & 0.004 \\
\hline
\end{tabular}

$\mathrm{LOH}$, loss of heterozygosity.

frequencies increased in $\mathrm{VC}$ compared with $\mathrm{VH}$, but did not reach statistical significance, reflecting the high degree of $\mathrm{LOH}$ already present in $\mathrm{VH}$ (any loss, $p$ $=0.07$; loss of more than one arm, $p=0.081$ ). With respect to specific arms, $9 p$ and $4 q$ showed a marginal increase between VH and VC $p=0.062$ and 0.053 , respectively). No difference in overall $\mathrm{LOH}$ frequencies was found between VC and $\operatorname{SCC}(p=1)$. However, the percentage loss at $4 q$ is actually higher in VC than in SCC $(p=0.041)$, although this may be due to the small sample size. SCC showed significantly increased loss on $17 p(p=0.037)$ compared with VC.

\section{Discussion}

Although VC is distinct from SCC in morphology and behavior, the genetic factors that might contribute to these clinicopathological differences are unknown. The development of SCC is associated with specific genetic alterations. Whether these same alterations are involved in the VC phenotype has not yet been demonstrated. The current paper is the first to examine $\mathrm{VC}$ and its precursor $\mathrm{VH}$ for $\mathrm{LOH}$ in multiple chromosomal regions that are frequently altered in dysplasia and SCC.

The data show that $\mathrm{VH}$ and $\mathrm{VC}$ share many of the losses present in dysplasia and SCC; however, these losses are accumulated differently. Conventional SCC progression is characterized by a gradual accumula-

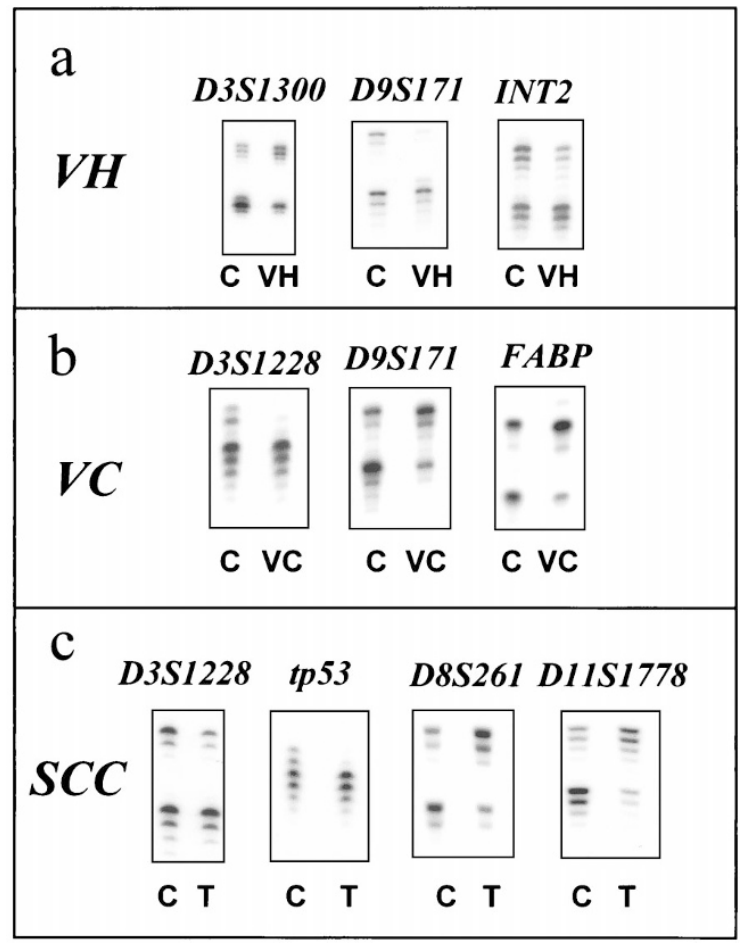

Figure 2.

Microsatellite analysis for three selected cases. Informative microsatellite markers were amplified from DNA derived from areas of epithelium containing lesion (including VH, VC, and SCC) or normal connective tissue stroma (C). Microsatellite markers being assayed are indicated above each block. a, Multiple loss of heterozygosity (LOH) in a case of VH (loss of the lower allele at D3S1300 and the upper allele at D9S171 and INT2). b, Multiple LOH in a case of VC (loss of the upper allele at D3S1228 and the lower allele at D9S171 and FABP). c, Multiple LOH in a case of SCC (loss of the upper allele at D3S1228 and tp53 and loss of the lower allele at D8S261 and D11S1778).

tion of LOH on different chromosomal arms (Califano et al, 1996; Rosin et al, 2000). For example, multiple loss, an indicator of malignant risk, is not seen in reactive hyperplasia ( $0 \%$ of cases in this study), but increases in frequency with increasing degree of dysplasia $(31 \%$ of low-grade dysplasia, $76 \%$ of highgrade dysplasia) and SCC (80\%). Some chromosomal regions are lost early in the progression $(3 p, 9 p$, and $17 p)$, whereas other losses occur later in high-grade dysplasias or SCC (4q, 8p, 11q, 13q) (Rosin et al, 2000). In contrast, $\mathrm{VH}$, as a precursor lesion, has a strikingly different $\mathrm{LOH}$ profile from that of reactive hyperplasia or low-grade dysplasia. The loss in $\mathrm{VH}$ is frequent (60\% with multiple losses) and often involves chromosome regions that are typically present only in 
Table 3. Verrucous Hyperplasia versus Dysplasia

\begin{tabular}{|c|c|c|c|c|c|}
\hline & VH & $\begin{array}{l}\text { Low-grade } \\
\text { dysplasia }^{a}\end{array}$ & $p^{\star}$ & $\begin{array}{l}\text { High-grade } \\
\text { dysplasia }\end{array}$ & $p^{\star *}$ \\
\hline Number of cases & 25 & 54 & - & 38 & - \\
\hline Mean loss & $2.28 \pm 1.7$ & $1.19 \pm 1.48$ & 0.0046 & $2.82 \pm 1.61$ & 0.21 \\
\hline Any loss & $20 / 25(80 \%)$ & $32 / 54(59 \%)$ & 0.081 & $36 / 38(95 \%)$ & 0.10 \\
\hline Loss of more than one arm & $15 / 25(60 \%)$ & $17 / 54(31 \%)$ & 0.026 & $29 / 38(76 \%)$ & 0.26 \\
\hline $\mathrm{LOH}$ on $3 p$ & $13 / 25(52 \%)$ & $13 / 53(25 \%)$ & 0.022 & $21 / 38(55 \%)$ & 1 \\
\hline $9 p$ & $11 / 24(46 \%)$ & $24 / 52(46 \%)$ & 1 & $27 / 37(73 \%)$ & 0.057 \\
\hline $4 q$ & $7 / 23(30 \%)$ & $4 / 48(8 \%)$ & 0.031 & $13 / 33(39 \%)$ & 0.58 \\
\hline $8 p$ & $7 / 24(29 \%)$ & $8 / 51(15 \%)$ & 0.22 & $9 / 32(28 \%)$ & 1.0 \\
\hline $11 q$ & $8 / 24(33 \%)$ & $6 / 52(12 \%)$ & 0.030 & $6 / 37(16 \%)$ & 0.13 \\
\hline $13 q$ & $4 / 22(18 \%)$ & $2 / 53(4 \%)$ & 0.057 & $8 / 33(24 \%)$ & 0.74 \\
\hline $17 p$ & $5 / 25(20 \%)$ & $11 / 54(20 \%)$ & 1 & $24 / 37(65 \%)$ & 0.0007 \\
\hline
\end{tabular}

${ }^{a}$ Cases reported in Rosin et al, 2000.

* Comparison of VH with low-grade dysplasia.

** Comparison of $\mathrm{VH}$ with high-grade dysplasia.

high-grade dysplasia or SCC. Indeed, VH and highgrade dysplasia differ only at one arm, 17p (significantly lower in $\mathrm{VH}$ ). The transition from $\mathrm{VH}$ to $\mathrm{VC}$ involves increases at $9 p$ and $4 q$ (approaching statistical significance, Table 4). VC is similar to SCC in LOH patterns except for lower frequencies of loss at $17 \mathrm{p}$.

The mechanism(s) that underlie such rapid accumulation of losses and the strikingly lower frequency of $\mathrm{LOH}$ at $17 \mathrm{p}$ is subject to speculation. The possibility of genetic instability in these lesions needs to be considered. Another possibility is a difference in etiology. The presentation of a remarkably verrucous configuration and cytological features of viral infection in VC have led to the conjecture of a viral etiology (Eisenberg et al, 1985). This supposition has only been supported by inconsistent reports of human papillomavirus (HPV) DNA in these verrucous lesions, with detection frequencies varying from $0 \%$ to $87.5 \%$ of cases (Palefsky et al, 1995; Shroyer and Greer, 1991; Shroyer et al, 1993). In a recent comprehensive study, Sidransky and co-workers reported a low rate of HPV in oral SCC (12\% of cases) (Gillison et al, 2000). However, other studies have reported different frequencies (Ostwald et al, 1994; Snijders et al, 1996). HPV etiology for oral cancer may be better evaluated with improvements in the detection of different types of HPV. Our data, that $\mathrm{VC}$ and $\mathrm{VH}$ show a strikingly lower frequency of loss at $17 \mathrm{p}$ (near or in the tp53 locus) in VC compared with SCC, is consistent with the hypothesis of an HPV etiology for the verrucous lesions. The low rate of $17 p$ loss could be explained by the assumption that p53 protein is inactivated by HPV protein through a ubiquitous pathway instead of through p53 mutation and chromosome losses (Gopalakrishnan et al, 1997).

It is well documented that $\mathrm{VH}$ is a high-risk premalignant lesion (with a reported malignant transformation rate of $70 \%$, Silverman and Gorsky, 1997). In fact, some even regard $\mathrm{VH}$ as an early or variant form of $\mathrm{VC}$ instead of as a premalignant lesion (Murrah and Batsakis, 1994; Slootweg and Muller, 1983). This high probability of transition may, in part, be explained by the $\mathrm{LOH}$ profiles in $\mathrm{VH}$. Not only are these profiles similar to those seen in high-grade dysplasia (with the exception of lower $17 \mathrm{p}$, Table 3) but also they resemble profiles characteristic of low-grade dysplasia at risk of progressing into cancer (Rosin et al, 2000).

The finding of the high-risk LOH profiles in the verrucous lesions has important clinical implications.

Table 4. Verrucous Carcinoma versus Verrucous Hyperplasia and Squamous Cell Carcinoma

\begin{tabular}{lccccc}
\hline & VC & VH & $p^{*}$ & SCC & $p^{* *}$ \\
\hline No. of cases & 17 & 25 & - & 41 & - \\
Mean loss & $3 \pm 1.32$ & $2.28 \pm 1.7$ & 0.15 & $3.6 \pm 1.8$ & 0.22 \\
Any loss & $17 / 17(100 \%)$ & $20 / 25(80 \%)$ & 0.070 & $39 / 41(95 \%)$ & 1 \\
Loss of more than one arm & $15 / 17(88 \%)$ & $15 / 25(60 \%)$ & 0.081 & $33 / 41(80 \%)$ & 0.71 \\
LOH on 3p & $10 / 17(59 \%)$ & $13 / 25(52 \%)$ & 0.76 & $29 / 40(73 \%)$ & 0.36 \\
$9 p$ & $13 / 17(77 \%)$ & $11 / 24(46 \%)$ & 0.062 & $27 / 39(69 \%)$ & 0.75 \\
$4 q$ & $11 / 17(65 \%)$ & $7 / 23(30 \%)$ & 0.053 & $13 / 39(33 \%)$ & 0.041 \\
$8 p$ & $6 / 17(35 \%)$ & $7 / 24(29 \%)$ & 0.74 & $20 / 39(51 \%)$ & 0.38 \\
$11 q$ & $5 / 16(31 \%)$ & $8 / 24(33 \%)$ & 1 & $20 / 40(50 \%)$ & 0.24 \\
$13 q$ & $2 / 15(13 \%)$ & $4 / 22(18 \%)$ & 1 & $15 / 38(39 \%)$ & 0.10 \\
$17 p$ & $4 / 16(25 \%)$ & $5 / 25(20 \%)$ & 0.72 & $24 / 14(60 \%)$ & 0.037 \\
\hline
\end{tabular}

${ }^{*} \mathrm{VH}$ versus $\mathrm{VC}$.

${ }^{* *}$ VC versus SCC. 
The lack of dysplasia or breakage of basement membrane makes it difficult to differentiate VH from reactive hyperplasia. Without these "gold standards," diagnosis of these lesions is often challenging for pathologists. In fact, some studies have shown that it took an average of three to four biopsies before a correct diagnosis of $\mathrm{VH}$ or VC could be made (Biller et al, 1971; Jordan, 1995). The sharp differences in $\mathrm{LOH}$ patterns between reactive hyperplasia and VH/VC suggest that microsatellite analysis may be a powerful tool for pathologists in the difficult diagnostic task of differentiating verrucous lesions from reactive lesions and may thus improve the prognosis of both $\mathrm{VH}$ and VC, because delay in diagnoses may result in anaplastic transformation of these lesions to SCC with increased mortality and morbidity (Hansen et al, 1985; Shear and Pindborg, 1980; Silverman and Gorsky, 1997).

\section{Materials and Methods}

\section{Sample Collection}

Specimens were selected from archival paraffin blocks obtained from the Provincial Oral Biopsy Service at Vancouver Hospital and Health Sciences Centre, Vancouver, Canada. Six groups of lesions were used: (1) 47 reactive lesions (14 hyperkeratotic reactive oral lesions that histologically demonstrate hyperkeratosis and/or acanthosis and 33 other reactive oral lesions, including fibroepithelial polyp, mucocele, periodontitis, traumatic ulcer); (2) $25 \mathrm{VH}$; (3) $17 \mathrm{VC}$; (4) 54 low-grade dysplasia (mild and moderate); (5) 38 highgrade dysplasia (severe dysplasia and CIS); and (6) 41 invasive oral SCC. The low-grade dysplasia cases were previously analyzed for $\mathrm{LOH}$ changes in a separate study (Rosin et al, 2000). Histological diagnoses of the specimens were reconfirmed by two authors ( $L Z$ and RP), both oral pathologists. The criteria used for the diagnosis of dysplasia were those established by the World Health Organization (WHO) Kramer et al (1978). Criteria for the diagnosis of VH and VC were those described by Shear and Pindborg (1980).

\section{Tissues Microdissection and DNA Extraction}

Areas of epithelial lesions (hyperplasia, VH, VC, dysplasia, CIS, or invasive SCC) were microdissected from sections stained with hematoxylin/eosin. The underlying stroma from each specimen was dissected and used as a source of matched control DNA. The microdissected tissues were digested in $300 \mu \mathrm{l}$ of 50 $\mathrm{mm}$ Tris- $\mathrm{HCl}(\mathrm{pH} 8.0)$ containing $1 \%$ sodium dodecyl sulfate (SDS) and proteinase $\mathrm{K}(0.5 \mathrm{mg} / \mathrm{ml})$ at $48^{\circ} \mathrm{C}$ and were spiked twice daily for 72 hours with $20 \mu \mathrm{l}$ of fresh proteinase $\mathrm{K}(20 \mathrm{mg} / \mathrm{ml})$. The DNA was extracted with phenol-chloroform and precipitated with ethanol as previously described (Baker et al, 1990). All samples were coded so that LOH analysis was performed without knowledge of diagnosis.

\section{LOH Assay}

The microsatellite markers used for $\mathrm{LOH}$ analysis came from Research Genetics (Huntsville, Alabama) and mapped to the following regions: 3p14.2 (D3S1234, D3S1228, D3S1300); 4q26 (FABP2); 4q31.1 (D4S243); 8p21.3 (D8S261); 8p23.3 (D8S262); 8p23.3 (D8S264); 9p21 (IFNA, D9S171, D9S1748, D9S1751); 11q13.3 (INT2); $11 \mathrm{q} 22.3$ (D11S1778); 13q12.3-13 (D13S170); 13q14.3 (D13S133); 17p11.2 (CHRNB1); and 17p13.1 (tp53 and D17S786). These markers are localized in regions previously shown to be frequently lost in head and neck SCC. The protocol used for LOH analysis was detailed in Zhang et al (1997). After PCR amplification, PCR products were separated on $7 \%$ urea-formamide-polyacrylamide gels and visualized by autoradiography. For informative cases, allelic loss was inferred when the signal intensity of one allele was at least $50 \%$ decreased in the DNA sample from a lesion, compared with the corresponding allele in the matching connective tissue DNA. All samples showing allelic loss were subjected to repeat analysis after a second independent amplification.

Statistical Analysis. The Fisher's exact, unpaired $t$ test and one way ANOVA were used for statistical analysis of the results. [Au: The following references have not been cited in the text: Batsakis et al, 1999; McCoy and Waldron, 1981; Medina et al, 1984.]

\section{References}

Ah-See KW, Cooke TG, Pickford IR, Soutar D, and Balmain A (1994). An allelotype of squamous carcinoma of the head and neck using microsatellite markers. Cancer Res 54:16171621.

Baker SJ, Preisinger AC, Jessup JM, Paraskeva C, Markowitz S, Willson JK, Hamilton S, and Vogelstein B (1990). p53 gene mutations occur in combination with $17 p$ allelic deletions as late events in colorectal tumorigenesis. Cancer Res 50:7717-7722.

Batsakis JG, Suarez P, and El-Naggar AK (1999). Proliferative verrucous leukoplakia and its related lesions. Oral Oncol 35:354-359.

Biller HF, Ogura JH, and Bauer WC (1971). Verrucous cancer of the larynx. Laryngoscope 81:1323-1329.

Califano J, van der Riet P, Westra W, Nawroz H, Clayman G, Piatadosi S, Corio R, Lee D, Greenberg B, Koch W, and Sidransky D (1996). Genetic progression model for head and neck cancer: Implications for field cancerization. Cancer Res $56: 2488-2492$.

Eisenberg E, Rosenberg B, and Krutchkoff DJ (1985). Verrucous carcinoma: A possible viral pathogenesis. Oral Surg Oral Med Oral Pathol 59:52-57.

Field JK, Kiaris H, Risk JM, Tsiriyotis C, Adamson R, Zoumpourlis V, Rowley H, Taylor K, Whittaker J, Howard P, Beirne JC, Gosney JR, Woolgar J, Vaughan ED, Spandidos DA, and Jones AS (1995). Allelotype of squamous cell carcinoma of the head and neck: Fractional allele loss correlates with survival. Br J Cancer 72:1180-1188. 
Gillison ML, Koch WM, Capone RB, Spafford M, Westra WH, Wu L, Zahurak ML, Daniel RW, Viglione M, Symer DE, Shah KV, and Sidransky D (2000). Evidence for a causal association between human papillomavirus and a subset of head and neck cancers. J Natl Cancer Inst 92:709-20.

Gopalakrishnan R, Weghorst CM, Lehman TA, Calvert RJ, Bijur G, Sabourin CLK, Mallery SR, Schuller DE, and Stoner GD (1997). Mutated and wild-type p53 expression and HPV integration in proliferative leukoplakia and oral squamous cell carcinoma. Oral Surg Oral Med Oral Pathol Oral Radiol Endod 83:471-477.

Hansen LS, Olson JA, and Silverman S, Jr (1985). Proliferative verrucous leukoplakia: A long-term study of 30 patients. Oral Surg Oral Med Oral Pathol 60:285-98.

Jacobson S and Shear M (1972). Verrucous carcinoma of mouth. J Oral Pathol 1:66-75.

Jordan RCK (1995). Verrucous carcinoma of the mouth. J Can Dent Assoc 61:797-801.

Kramer IR, Lucas RB, Pindborg JJ, and Sobin LH (1978). Definition of leukoplakia and related lesions: An aid to studies on oral precancer. Oral Surg Oral Med Oral Pathol 46:517539.

Mao L (2000). Can molecular assessment improve classification of head and neck premalignancy? Clin Cancer Res 6:321-322.

Mao L, Lee JS, Fan YH, Ro JY, Batsakis JG, Lippman S, Hittleman W, and Hong WK (1996). Frequent microsatellite alterations at chromosomes 9p21 and 3p14 in oral premalignant lesions and their value in cancer risk assessment. Nat Med 2:682-685.

McCoy JM and Waldron CA (1981). Verrucous carcinoma of the oral cavity. A review of forty-nine cases. Oral Surg Oral Med Oral Pathol 52:623-629.

Medina JE, Dichtel W, and Luna MA (1984). Verrucoussquamous carcinomas of the oral cavity, a clinicopathologic study of 104 cases. Arch Otolaryngol 110:437-440.

Murrah VA and Batsakis JG (1994). Proliferative verrucous leukoplakia and verrucous hyperplasia. Ann Otol Rhinol Laryngol 103:660-663.

Ostwald C, Muller P, Barten M, Rutsatz K, Sonnenburg M, Milde-Langosch K, and Loning T (1994). Human papillomavirus DNA in oral squamous cell carcinomas and normal mucosa. J Oral Pathol Med 23:220-225.

Palefsky JM, Silverman S, Jr, Abdel-Salaam M, Daniels TE, and Greenspan JS (1995). Association proliferative verrucous leukoplakia with human papilloma virus type 16. J Oral Pathol Med 24:193-197.

Partridge M, Emilion G, Pateromichelaskis S, A'Hern R, Philips E, and Langdon J (1998). Allelic imbalance at chromosomal loci implicated in the pathogenesis of oral precancer, cumulative loss and its relationship with progression to cancer. Oral Oncol 34:77-83.
Rosin MP, Cheng X, Poh C, Lam W, Huang Y, Lovas J, Berean K, Epstein JB, Priddy R, Le ND, and Zhang L (2000). Use of allelic loss to predict malignant risk for low-grade oral epithelial dysplasia. Clin Cancer Res 6:357-362.

Rosin MP, Epstein JB, Berean K, Durham S, Hay J, Cheng X, Zeng T, Huang $Y$, and Zhang $L$ (1997). The use of exfoliative cell samples to map clonal genetic alterations in the oral epithelium of high-risk patients. Cancer Res 57:5258-5260.

Roz L, Wu CL, Porter S, Scully C, Speight P, Read A, Sloan $P$, and Thakker N (1996). Allelic imbalance on chromosome $3 p$ in oral dysplastic lesions: An early event in oral carcinogenesis. Cancer Res 56:1228-1231.

Shear M and Pindborg JJ (1980). Verrucous hyperplasia of the oral mucosa. Cancer 46:1855-1862.

Shroyer KR and Greer RO, Jr (1991). Detection of human papillomavirus DNA by in situ DNA hybridization and polymerase chain reaction in premalignant and malignant oral lesions. Oral Surg Oral Med Oral Pathol 71:708-713.

Shroyer KR, Greer RO, Fankhouser CA, McGuirt WF, and Marshall R (1993). Detection of human papillomavirus DNA in oral verrucous carcinoma by polymerase chain reaction. Mod Pathol 6:669-672.

Silverman S Jr and Gorsky M (1997). Proliferative verrucous leukoplakia. A follow-up study of 54 cases. Oral Surg Oral Med Oral Pathol 84:154-157.

Slootweg PJ and Muller H (1983). Verrucous hyperplasia or verrucous carcinoma. An analysis of 27 patients. J Maxillofac Surg 11:13-19.

Snijders PJF, Scholes AGM, Hart CA, Jones AS, Vaughan ED, Woolgar JA, Meijer CJLM, Walboomers JMM, and Field JK (1996). Prevalence of mucosotropic human papillomaviruses in squamous-cell carcinomas of the head and neck. Int J Cancer 66:464-469.

Zhang L, Cheng X, Li YH, Poh C, Zeng T, Priddy R, Lovas J, Freedman P, Daley T, and Rosin MP (2000). High frequency of allelic loss in dysplastic lichenoid lesions. Lab Invest 80:233-237.

Zhang L, Michelsen C, Cheng X, Zeng T, Priddy R, and Rosin MP (1997). Molecular analysis of oral lichen planus: A premalignant lesion? Am J Pathol 8:323-327.

Zhang L, Poh CF, Lam WL, Epstein JB, Cheng X, Zhang X, Priddy R, Lovas J, Le ND and Rosin MP (In press, 2001). Impact of localized treatment in reducing risk of progression of low-grade oral dysplasia: Molecular evidence of incomplete resection. Oral Oncol. 